\title{
Complementary and alternative medicine - practice, attitudes, and knowledge among healthcare professionals in New Zealand: an integrative review
}

\author{
Lizhou Liu ${ }^{1,2^{*}}$ (D, Yong Tang ${ }^{3,4,5}$, G. David Baxter ${ }^{1,2}$, Haiyan Yin ${ }^{3,4,5}$ and Steve Tumilty ${ }^{1,2}$
}

\begin{abstract}
Background: The prevalence of CAM use is increasing. This integrative review investigated New Zealand healthcare professionals' practice of, attitudes toward, and knowledge about complementary and alternative medicine (CAM).

Methods: Literature search was conducted in four databases from inception to April 2020. Studies were included if they reported results from primary data collection on practice of, attitudes toward, or knowledge about CAM amongst New Zealand healthcare professionals.

Results: Eleven studies (two of 'high-quality', seven of 'moderate-quality', and two of 'low-quality') were identified with 2060 healthcare professionals including general practitioners (GPs), nurses, midwives, pharmacists,

physiotherapists, and medical specialists. New Zealand healthcare professionals were generally positive regarding CAM use, but have concerns on the scientific evidence, regulation, safety, financial costs of CAM, and encourage an evidence-based CAM practice and stronger CAM regulation. Findings indicated that around 25\% of GPs practise CAM, and $82.3 \%$ refer patients to CAM practitioners. When treating pregnant women, $48.4 \%$ of physiotherapists practise acupuncture, and $37.3 \%$ of midwives recommend CAM. GPs believe that acupuncture is the most helpful CAM modality, and most commonly practiced and referred patients to acupuncture. Up to 58\% of GPs and Plunket nurses wanted to receive further education on CAM, and up to $66.7 \%$ GPs favour the idea CAM should be included in medical curriculums.

Conclusions: Nine of the 11 included studies were of moderate to high quality, thus enhancing the reliability of the review findings. In order to better manage CAM in New Zealand New Zealand clinical settings, there is a need to invest in CAM research and education, and enhance CAM regulation. This review is a first step in developing an evidence base to offer insights for further development of effective CAM policies regarding safety, efficacy, regulation and integration in New Zealand.
\end{abstract}

Keywords: Complementary and alternative medicine, New Zealand, Healthcare practitioners, Practice, Attitudes, Knowledge

\footnotetext{
* Correspondence: lizhou.liu@otago.ac.nz

'Centre for Health, Activity, and Rehabilitation Research, School of

Physiotherapy, University of Otago, PO Box 56, Dunedin 9054, New Zealand

${ }^{2}$ China-New Zealand Collaboration Centre for Integrative Medicine

(CHINZIM), University of Otago, Dunedin, New Zealand

Full list of author information is available at the end of the article
} 


\section{Background}

Complementary and alternative medicine (CAM) is an umbrella term describing a range of health systems, modalities, and practices that are not generally considered part of conventional medicine. CAM modalities are divided into five main categories by the American National Center for Complementary and Integrative Health: alternative medical systems, biologically based treatments, manipulative and bodybased methods, mind-body interventions, and energy therapies [1]. In New Zealand, it is estimated that there are 69 CAM modalities available [2].

Similar to other developed countries, public interest in and use of CAM in New Zealand has increased over the last decades, although CAM research is limited in this country. It has previously been reported by three regional surveys (2003-2006) that CAM therapies was used by $67 \%$ of patients at medical practices [3], 38\% of emergency department presenters [4], and $49 \%$ of cancer patients [5]. The most recent national health survey (2006-2007) found that nearly one in five adults visited a CAM practitioner in the previous 12 months, with the number of women being significantly higher than men [6]. The types of CAM used were most commonly seeing a massage therapist, followed by a homoeopath or naturopath, and an acupuncturist (visits of chiropractor and osteopath were separately evaluated in this survey) [6].

Recognizing the potential impact of CAM on patient care, CAM is slowly gaining political recognition in New Zealand. The Ministerial Advisory Committee on Complementary and Alternative Health (MACCAH) was established in June 2001, in direct response to a request by the Ministry of Health. The committee finished its term in June 2004, providing information and advice to the Minister on complementary and alternative healthcare focusing on areas of regulation, consumer information needs, research, and integration [7]. In addition, at the national level, the Accident Compensation Corporation (ACC) provides compulsory no-fault personal injury cover for treatment for all New Zealand residents and visitors to New Zealand, which includes cover for acupuncture, chiropractic and osteopathy. This funding stream results in increasing numbers of patients who use CAM therapies in conjunction with mainstream medicine, and in turn the development of closer ties between CAM practitioners and a range of conventional healthcare professions in New Zealand. While the focus for evidence in CAM has been increasingly recognized at a national level, in 2018, the ACC undertook a review to synthesize the published academic literature on the effectiveness and safety of acupuncture interventions for the treatment of musculoskeletal conditions and injuries
[8], indicating the emerging research on CAM in New Zealand.

Healthcare professionals' attitudes toward and knowledge about CAM are important for patient care decision making, as they may affects the option of a multidisciplinary healthcare approach [9]. In addition, healthcare professionals' beliefs and practice behaviours of CAM can significantly impact the development of CAM professions and their role in the healthcare system, despite studies that demonstrate the public's desire for the integration of certain CAM modalities into the mainstream health system [8]. A literature review summarizing 21 surveys of physicians, nurses, public health professionals, dieticians, social workers, medical and nursing faculty, and pharmacists in Canada and United States, concluded that while physicians are more negative than other healthcare professionals, positive attitudes toward CAM are not related to CAM referral or prescription patterns [10]. It is unknown whether these findings are representative of healthcare professionals in other countries. Furthermore, as this review was published over ten years ago, the relevance of the reported findings may not be contemporary.

In New Zealand, the regulated health professional workforce numbered 97,786 in 2015 [11]. A number of localized surveys on specific practitioners' use of and attitudes towards CAM (e.g., general practitioners [GPs]) have been conducted in New Zealand over the past 25 years $[3,8,12-15]$. There has yet to be a study evaluating the overall practice of, attitudes toward, and knowledge about CAM therapies among various categories of New Zealand healthcare professionals. This gap in the literature is particularly important given that conventional healthcare professionals are often reported to be reluctant or lacking in confidence to advise patients on the use of CAM, and therefore issues such as safety, effectiveness, and practicality of CAM use may be overlooked [9]. It will be useful to know their perceptions, knowledge and clinical behaviours related to CAM therapies and practitioners in order to inform further development of evidence-based CAM in New Zealand, e.g. in terms of the methodological design of clinical research, as well as the development of education packages for New Zealand healthcare professionals. This information will be of importance to further CAM development in New Zealand, in order to develop effective policies based on effectiveness, safety, regulation and integration [8].

The primary aim of this review was to summarize the results of existing studies (both quantitative and qualitative) that investigated New Zealand healthcare professionals' practice of, attitudes towards, and knowledge about CAM. In addition, the secondary aim was to explore whether the CAM practice, attitudes, and knowledge are different amongst healthcare professionals or 
change over time. For these purposes, an integrative review approach was adopted, which allows for the combination of diverse methodologies to capture the context, processes, and subject elements of this topic [16].

\section{Methods}

The methods for this review were consistent with the methodology framework for integrative reviews [16]. The protocol of this review was not registered. This review was reported in accordance to the Preferred Reporting Items for Systematic Reviews and Meta-Analyses (PRISMA) guidelines [17].

\section{Eligibility criteria}

Studies were included if they met the following criteria:

1 Population: New Zealand healthcare professionals regulated under the Health Practitioners Competence Assurance (HPCA) Act 2003 [18].

2 Outcome measures: practice, use, recommendation, attitudes, views, and knowledge of CAM.

3 Study type: both quantitative and qualitative studies that reported results on original empirical research findings. Reviews, study protocols, correspondence, commentaries, and letters were excluded.

\section{Search strategy}

A comprehensive literature search was conducted by two independent researchers (LL and YT) in AMED, CINAHL, EMBASE, MEDLINE from inception to April 2020. The search strategy was developed following consultation with a health sciences librarian (Table 1). The four themes were combined with "AND", while the individual terms in each theme combined with "OR". The MEDLINE strategy was first finalized and then adapted for search in other databases. There were no limitations on language or year of publication. Reference lists of included studies and relevant reviews were manually searched for additional references.

\section{Selection of studies}

Titles, abstracts, and full text of potential articles were reviewed by two independent reviewers (LL and YT) for eligibility. Consensus was reached by discussion, and a third reviewer (ST) involved for the final decision where disagreement persisted.

\section{Data extraction}

Data were extracted from the included studies by the first author (LL), and separately reviewed by a second reviewer (YT). Findings were compared and agreed upon discussion. Further data were obtained through email contacts with corresponding authors if necessary. The

Table 1 Summary of the search terms

\begin{tabular}{|c|c|c|c|c|}
\hline \multicolumn{2}{|l|}{ THEME 1: CAM terms } & \multirow{2}{*}{$\begin{array}{l}\text { THEME 2: } \\
\text { Outcomes }\end{array}$} & \multirow{2}{*}{$\begin{array}{l}\text { THEME 3: Healthcare } \\
\text { professional terms }\end{array}$} & \multirow{2}{*}{$\begin{array}{l}\text { THEME 4: } \\
\text { Limiters }\end{array}$} \\
\hline Broad descriptor headings & Specific headings & & & \\
\hline alternative medicine/therapy & acupuncture & attitude* & consultant* & Aotearoa \\
\hline CAM & aromatherapy & belief* & dental* & Māori \\
\hline complementary and alternative medicine & chiropractic & knowledge* & dentist* & New Zealand \\
\hline complementary medicine/therapy & dietary supplements & perception* & dietitian* & \\
\hline integrative medicine/therapy & herb* medicine & perspective* & doctor* & \\
\hline \multirow[t]{14}{*}{ traditional medicine/therapy } & homeopathy & practice* & general practitioner* & \\
\hline & hypno* & recommendation* & health* professional* & \\
\hline & massage & $u_{s e}^{*}$ & midwi* & \\
\hline & meditation & value* & nurse ${ }^{*}$ & \\
\hline & naturopathy & view$^{*}$ & occupational therapist* & \\
\hline & osteopathy & & oral health therapists* & \\
\hline & reflexology & & paramedic* & \\
\hline & rongoā & & pharmacist* & \\
\hline & spiritual healing & & physiotherapist* & \\
\hline & traditional Chinese medicine & & podiatrist* & \\
\hline & traditional Māori medicine & & psychologist* & \\
\hline & traditional Pacific Island medicine & & psychotherapist* & \\
\hline & vitamins & & optometrist* & \\
\hline & yoga & & & \\
\hline
\end{tabular}


window for response was set at four weeks; a follow up email was sent to non-responders after three weeks. Required information included general information (first author and year of publication), study characteristics (study design, sampling method, sample size, response rate, and the investigated CAM therapies), participant characteristics (target population, age, ethnicity, and gender), and three key themes of investigation emerged from included studies ('prevalence of practice, use and referral', 'attitudes and views', 'knowledge and education).

\section{Quality assessment}

Methodological quality of included studies was assessed by two independent reviewers (LL and YT) with disagreement resolved through consensus method. The quality of quantitative studies was assessed using the Hoy's risk of bias tool for observational studies [19]. This 10-item checklist addresses four domains of bias (selection bias, nonresponse bias, measurement bias, and bias related to the analysis) plus a summary risk of bias assessment. The summary assessment evaluates the overall risk of study bias (low, moderate, high) which is based on the reviewer's judgment given responses to the preceding ten items. The quality of qualitative studies was assessed using the Critical Appraisal Skills Programme (CASP) (2018) for qualitative research [20]. The CASP checklist assesses 10 questions that are considered important for appraising the quality of qualitative research: aim, methodology, design, recruitment strategy, data collection, relationship between researcher and participants, ethical issues, data analysis, findings statement, and research value. No formal rating scale for this checklist is available; therefore, for the purpose of this review, a rating system previously used in other reviews was employed: a study was considered as 'high' quality if the total score was over $6,4-6$ as 'moderate' quality, and less than 4 as 'low' quality [21, 22].

\section{Data synthesis}

The data from included studies were grouped and summarized in a narrative manner in accordance with the three key themes. CAM practice, attitudes and knowledge among different categories of healthcare professionals were compared where data permitted. Changes in CAM practice, attitudes and knowledge over time were summarized by professional categories.

\section{Results}

\section{Study selection}

A total of 285 articles were identified using the search criteria. After removing 97 duplicates, 168 were excluded based on titles and abstracts, and 20 screened for full text for eligibility. Eleven articles met the selection criteria, and were included in this review. Of the nine excluded articles, two were discussion papers [23, 24], two reported international studies without data specific to New Zealand [25, 26], two reported outcomes irrelevant to this review [27, 28], and the remaining three were a review [29], a commentary [30], and a letter [31]. Figure 1 displays the process of study selection.

\section{Study characteristics}

Characteristics of the 11 included studies are presented in Table 2. A total of 2060 healthcare professionals were included, with a range of 5 to 500 participants per study. The investigated healthcare professionals included GPs ( $n=7$ studies) [3, 8, 12-15, 33], Plunket nurses (registered child health nurses working in the community) $(n=1)$ [9], midwives $(n=1)$ [32], pharmacists $(n=1)$ [34], physiotherapists $(\mathrm{n}=1)$ [35], and specialists $(\mathrm{n}=1)$ [15]. The CAM modalities investigated in the studies varied greatly: one study [35] focused solely on acupuncture, one [8] (mainly) on massage, two [12,14] on a variety of CAM therapies from the list selected from the NCCAM, including acupuncture, aromatherapy, chiropractic, herbal medicines, homeopathy, hypnosis, naturopathy, osteopathy, reflexology, spiritual healing, traditional Chinese Medicine, traditional Māori Medicine, traditional Pacific Island Medicine; the remaining seven $[3,9,13,15,32-34]$ did not specify the definition of CAM. Most participants were middle aged, New Zealand European. Of the 11 included studies, there were eight surveys $[3,8,12-15,32,35,36]$ and three qualitative studies (two interviews [33,34] and one focus group study [9]).The sampling methods used included census $(n=4)$ [3, 12, 15, 35], convenience $(n=1)$ [9], simple random $(n=3)[8,13,14]$, systematic random $(n=1)$ [32], stratified $(\mathrm{n}=1)$ [33], and a mixed use of purposive and convenience approaches $(\mathrm{n}=1)$ [34]. Instruments used in the eight surveys varied, without psychometric properties reported; four studies used instruments that were developed and adapted from previous studies [8, $14,15,35]$. Response rates for surveys ranged from $43 \%$ [8] to $83.3 \%$ [3]. Two studies were of 'high' quality [9, $34]$, seven of 'moderate' quality [3, 8, 12, 14, 32, 33, 35], and two of 'low' quality [13, 15] according to the Hoy's critical appraisal tool and CASP checklist (see Additional files 1 and 2).

\section{Prevalence of practice, use and referral for CAM}

The practice, self-use, and referral for patients to CAM therapies by healthcare professionals appears common in a New Zealand clinical setting. The prevalence of CAM practice ranged from $20.3 \%$ [14] to $30.1 \%$ [13] among GPs, and $48.4 \%$ among physiotherapists when treating women during pregnancy [35]. It was reported that $47 \%$ of GPs personally use massage [8], and 


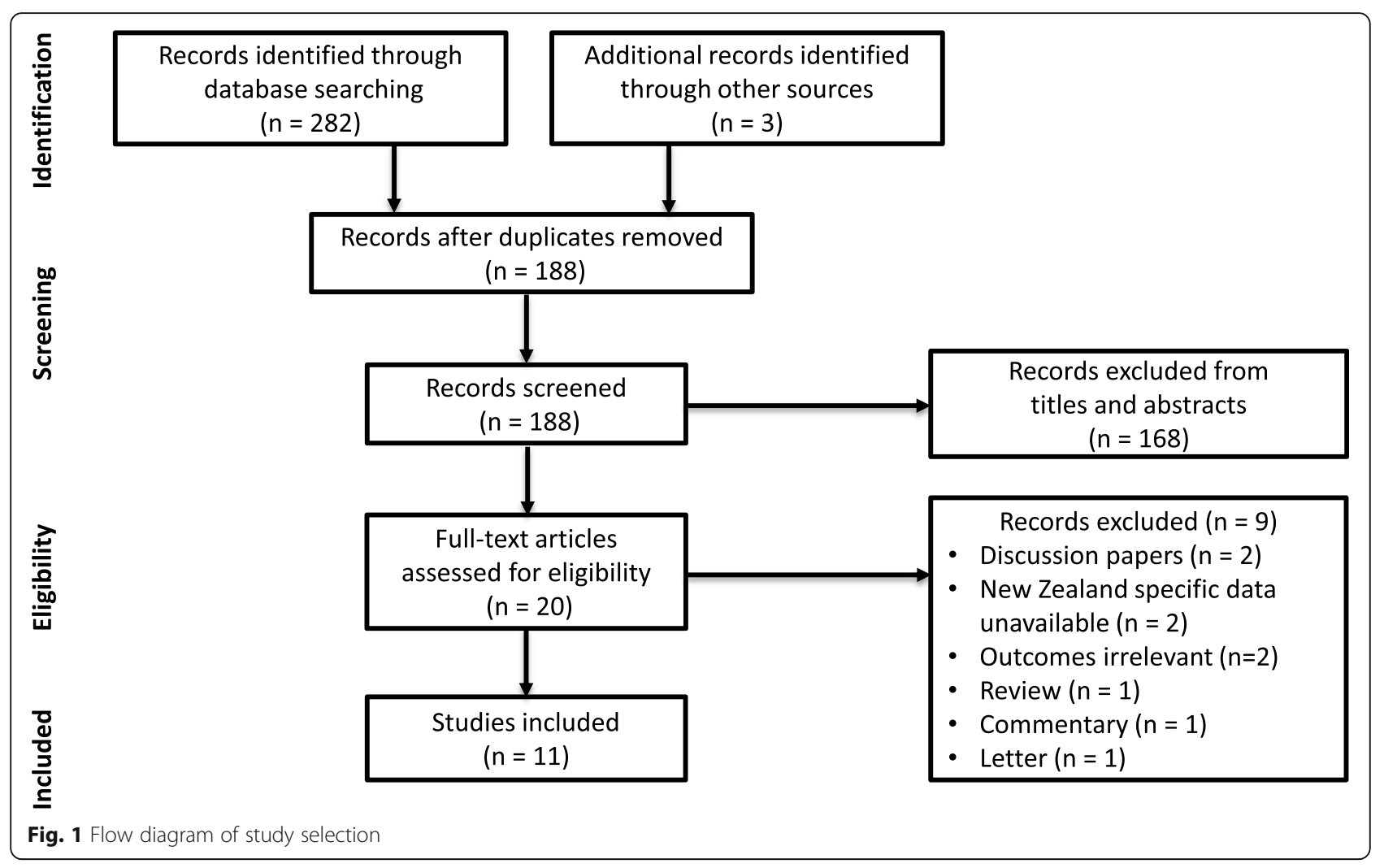

approximately $26 \%$ of GPs and specialists use CAM to treat their own ailments [15]. The proportion of professionals reporting CAM referrals ranged from 37.3\% [32] to $94.7 \%$ [14].

Reported reasons for using CAM therapies included failure of conventional treatment, patient request, past positive experience, and to complement existing treatment $[13,14]$. Two surveys examined medical conditions that healthcare professionals would consider treating with CAM therapies $[8,35]$. The majority of GPs would consider recommending CAM to patients with musculoskeletal problems, pain, back problems, and for women's health [8]. When treating pregnant women, physiotherapists used acupuncture for pregnancy-related complaints, including musculoskeletal pain, nausea, induction of labour, and breech presentation [35].

\section{Attitudes and views toward CAM}

Out of the eight survey studies, healthcare professionals' attitudes and views toward CAM were evaluated as a dichotomous outcome (either positive or negative toward CAM therapy use) [13] or in the form of statement agreement $[8,14,15,32]$. In general, seven studies (five surveys, one focus group study, and one interview study) reported an overall positive attitude regarding use of CAM therapies $[8,9,13-15,32,33]$. Reasons in support of CAM use included the effectiveness of CAM and the view that $\mathrm{CAM}$ as a useful complement to conventional treatments [13]. On the other hand, perceived lack of evidence, lack of regulation, potential side effects, interference with other medications, and the financial cost for CAM represented the major concerns about CAM among GPs [13-15]. For Plunket nurses, despite positive perspectives on CAM, the organizational policy constraints and possible liability in engaging with CAM were the most significant barriers for CAM recommendation [9].

Surveys focusing on GPs showed that the majority of GPs insist on the need for an evidence base for CAM therapies, and encourage more scientific testing of CAM therapies before being used to complement conventional medicine $[8,14]$. Notwithstanding this, findings of indepth interviews with GPs acknowledged the importance of the patient-centred element that CAM therapies provide as being as important as the evidence-base [33]. For midwives, understanding and perception of CAM is closely linked to the philosophy, care perspectives, and professional goals of midwifery practice; over $70 \%$ of midwives perceived that CAM is an essential and traditional part of midwifery practice, and that the use of CAM enhances midwifery care [32].

Five studies $[3,9,14,15,35]$ showed that on average $45.3 \%$ of healthcare professionals have concerns on the safety of CAM therapies. In particular, $87 \%$ of GPs and specialists were concerned about the safety of CAM use for oncology patients [15]. 
Table 2 Characteristics of the 11 studies included in the review

\begin{tabular}{|c|c|c|c|c|c|c|c|c|c|c|c|}
\hline \multirow[t]{2}{*}{ Author (Year) } & \multirow[t]{2}{*}{ Method } & \multirow{2}{*}{$\begin{array}{l}\text { Target } \\
\text { population }\end{array}$} & \multirow{2}{*}{$\begin{array}{l}\text { Investigated } \\
\text { CAM therapies }\end{array}$} & \multirow{2}{*}{$\begin{array}{l}\text { Sample } \\
\text { size/RR }\end{array}$} & \multirow{2}{*}{$\begin{array}{l}\text { Sampling } \\
\text { method }\end{array}$} & \multirow{2}{*}{$\begin{array}{l}\text { Main age } \\
\text { group (\%) }\end{array}$} & \multirow{2}{*}{$\begin{array}{l}\text { Ethnicity (NZ } \\
\text { European \%) }\end{array}$} & \multirow{2}{*}{$\begin{array}{l}\text { Male } \\
(\%)\end{array}$} & \multicolumn{2}{|c|}{ Theme $^{d}$} & \multirow{2}{*}{$\begin{array}{l}\text { Study } \\
\text { quality }\end{array}$} \\
\hline & & & & & & & & & I II & $\overline{\text { III }}$ & \\
\hline $\begin{array}{l}\text { Hadley } \\
\text { (1988) [12] }\end{array}$ & Survey & GPS & $\begin{array}{l}\text { Seven CAM } \\
\text { therapies }^{\mathrm{a}}\end{array}$ & $226 / 77 \%$ & Census & $\begin{array}{l}30-50 \mathrm{yr} \\
(58 \%)\end{array}$ & NR & 75 & $\sqrt{ } \times$ & $\sqrt{ }$ & Moderate \\
\hline $\begin{array}{l}\text { Marshall } \\
\text { (1990) [13] }\end{array}$ & Survey & GPs & NS & $\begin{array}{l}370 / \\
67.3 \%\end{array}$ & Simple random & Mean $=44 \mathrm{yr}$ & 84.7 & 82.6 & $\sqrt{ } \sqrt{ }$ & $\sqrt{ }$ & Low \\
\hline $\begin{array}{l}\text { Taylor (2003) } \\
\text { [3] }\end{array}$ & Survey & GPs & NS & $\begin{array}{l}30 / \\
83.3 \%\end{array}$ & Census & NR & NR & NR & $\sqrt{ } \sqrt{ }$ & $\sqrt{ }$ & Moderate \\
\hline $\begin{array}{l}\text { Lawler (2004) } \\
\text { [8] }\end{array}$ & Survey & GPs & $\begin{array}{l}\text { Massage and } \\
\text { other CAM }\end{array}$ & $200 / 43 \%$ & Simple random & $\begin{array}{l}\text { Mean }=46.1 \\
y r\end{array}$ & 73 & 57 & $\sqrt{ } \sqrt{ }$ & $\sqrt{ }$ & Moderate \\
\hline $\begin{array}{l}\text { Poynton } \\
\text { (2006) [14] }\end{array}$ & Survey & GPs & $\begin{array}{l}\text { Thirteen CAM } \\
\text { therapies }^{\mathrm{b}}\end{array}$ & $500 / 60 \%$ & Simple random & $\begin{array}{l}\text { Mean }=50.3 \\
\mathrm{yr}\end{array}$ & 72 & 60 & $\sqrt{ } \times$ & $\sqrt{ }$ & Moderate \\
\hline $\begin{array}{l}\text { Harding } \\
\text { (2009) [32] }\end{array}$ & Survey & Midwives & NS & $\begin{array}{l}171 / \\
44.6 \%\end{array}$ & $\begin{array}{l}\text { Systematic } \\
\text { random }\end{array}$ & NR & NR & NR & $\sqrt{ } \sqrt{ }$ & $\times$ & Moderate \\
\hline $\begin{array}{l}\text { Bocock } \\
\text { (2011) [15] }\end{array}$ & Survey & $\begin{array}{l}\text { GPs \& } \\
\text { specialists }\end{array}$ & NS & $395 / 59 \%$ & Census & $\begin{array}{l}41-50 \mathrm{yr} \\
(36 \%)\end{array}$ & 88 & 66 & $\sqrt{ } \sqrt{ }$ & $\sqrt{ }$ & Low \\
\hline $\begin{array}{l}\text { Upsdell } \\
\text { (2011) [33] }\end{array}$ & Interview & GPs & NS & 12 & Stratified & NR & NR & NR & $\times \sqrt{ }$ & $\sqrt{ }$ & Moderate \\
\hline Lo (2012) [9] & $\begin{array}{l}\text { Focus } \\
\text { group }\end{array}$ & $\begin{array}{l}\text { Plunket } \\
\text { nurses }\end{array}$ & NS & 5 & Convenience & $\begin{array}{l}20-40 \mathrm{yr} \\
(100 \%)\end{array}$ & 60 & 0 & $\times \sqrt{ }$ & $\sqrt{ }$ & High \\
\hline $\begin{array}{l}\text { Barnes (2018) } \\
\text { [34] }\end{array}$ & Interview & Pharmacists & NS & 27 & $\begin{array}{l}\text { Purposive \& } \\
\text { convenience }\end{array}$ & $\begin{array}{l}40-49 y r \\
(44.4 \%)\end{array}$ & $N R$ & 51.9 & $\times \sqrt{ }$ & $\sqrt{ }$ & High \\
\hline $\begin{array}{l}\text { McDowell } \\
\text { (2019) [35] }\end{array}$ & Survey & Physios & Acupuncture & $124 / N R$ & Census & $\begin{array}{l}30-40 y r \\
(38.7 \%)\end{array}$ & NR & 21 & $\sqrt{ } \sqrt{ }$ & $\sqrt{ }$ & Moderate \\
\hline
\end{tabular}

Abbreviations: NS not specified, GPs general practitioners, CAM complementary and alternative medicine, NZ New Zealand, physios physiotherapists, RR response rate

a The specified seven therapies were hypnosis, acupuncture, osteopathy, chiropractic, naturopathy, homeopathy and spiritual healing

b The specified thirteen therapies were acupuncture, aromatherapy, chiropractic, herbal medicines, homeopathy, hypnosis, naturopathy, osteopathy, reflexology, spiritual healing, traditional Chinese Medicine, traditional Māori Medicine, traditional Pacific Island Medicine

${ }^{c}$ RR applied to survey studies only

${ }^{d} \mathrm{I}=$ prevalence of practice, use and referral for CAM; $\mathrm{I}=$ attitudes and views toward CAM, III = knowledge and education regarding CAM

Two studies $[12,13]$ found no significant difference in the practicing patterns of CAM use by GPs by gender or age. Female, younger, and community doctors were more likely than their male, older, and hospital colleagues to refer patients to CAM practitioners $[13,15]$.

\section{Knowledge and education regarding CAM}

Of the 11 studies included in this review, four $[3,8,12$, 13] reported healthcare professionals' knowledge about CAM therapies. Knowledge about CAM was assessed by asking 1) whether healthcare professionals were familiar with or had heard of CAM therapies [8, 12], and 2) whether they knew local CAM practitioners [3, 12, 13]. In general, acupuncture is the most well-known CAM therapy among GPs $[8,12]$. The mean percentage who knew local CAM practitioners was $84.7 \%$ with the highest rate of $94 \%$ [12]. A majority of GPs commented that they were unfamiliar with rongoā Māori and traditional Pacific Island medicine [3, 14]. Workshops, reading the literature, and discussions with colleagues were the major sources of obtaining CAM knowledge [32]. GPs expressed the need for ongoing peer support as well as access to reliable and unbiased CAM knowledge resources [33]. Approximately $38 \%$ of doctors felt comfortable discussing CAM use with patients $[14,15]$, and over $90 \%$ asked patients about their CAM use during consultation $[3,15]$, although only $40.6 \%$ initiated the discussion [32].

Four studies reported on issues associated with professionalism [3, 8, 33, 34]. Approximately $85 \%$ of GPs would like to see better regulation of CAM practitioners and products $[3,8]$. It was reported that professional issues are important if GPs were considering any form of networking with CAM practitioners [33]. Community pharmacists recognized the current inadequacy of CAM regulations in New Zealand, and supported a national regulatory framework for both CAM practitioner and products to address concerns regarding CAM product quality, inappropriate health claims, and supporting evidence; there were mixed views as to whether regulation should be mandatory or self-regulation [34].

Findings indicated that approximately one quarter of GPs have received formal training in CAM [3, 12-14, 33], while $44.4 \%$ of physiotherapists received (postgraduate) training in acupuncture [35]. Surprisingly, it would appear that a number of GPs practised CAM therapies 
without training (i.e., acupuncture, chiropractic, and hypnosis) [12]. Interest in CAM among New Zealand healthcare professionals is high: up to $58 \%$ of GPs wished to receive further education on CAM $[3,8,12$, 14, 15]; moreover, a focus group study reported that all Plunket nurses wished to increase their knowledge about CAM modalities [9]. The two therapies in which GPs were the most interested in receiving training were acupuncture, and herbal medicine [14]. Interest in training declined in GPs aged over 50 years [12]. There is evidence that many healthcare professionals identify gaining knowledge about CAM as an important professional issue, and up to $66.7 \%$ GPs support the idea that an overview of CAM should be included into initial medical education $[3,14]$.

\section{Difference in CAM practice, attitudes and knowledge between healthcare professionals}

Due to the wide variation in CAM therapies covered across the included studies, head-to-head comparisons between different categories of healthcare professionals could not be performed. Descriptive summaries from each discipline (when data were available) are reported above.

\section{Changes in CAM practice, attitudes, and knowledge over time}

Due to the limited number of studies on healthcare professionals other than GPs, only changes in GPs' behaviours over time (based on data from five studies [3, 8 , 12-14]) were evaluated (Fig. 2). In general, practice of CAM has slightly decreased since 1990, but the number of GPs trained in CAM has increased over time. Referral patterns for CAM fluctuated. Acupuncture is the most useful CAM therapy from GPs' perspective, and is also the most commonly practiced, and referred CAM therapy by GPs over time (Tables 3, 4 and 5).

\section{Discussion}

This is the first review that investigated New Zealand healthcare professionals' practice of, attitudes toward, and knowledge about CAM. Review of the literature found 11 studies conducted with a total of 2060 healthcare professionals including GPs, Plunket nurses, midwives, pharmacists, physiotherapists, and specialists. Findings indicated that CAM use is common among New Zealand healthcare professionals: around 25\% of GPs practise CAM, and $82.3 \%$ refer patients to CAM practitioners; when treating pregnant women, $48.4 \%$ of physiotherapists practise acupuncture, and $37.3 \%$ of midwives recommend CAM. GPs believe that acupuncture is the most useful CAM modality, and most commonly practiced and referred patients to acupuncture. New Zealand healthcare professionals are overall positive regarding CAM use, but have concerns on the scientific evidence, regulation, safety, financial costs of CAM, and encourage an evidence-based CAM practice and a stronger CAM regulation. Up to 58\% of GPs and Plunket nurses wanted to receive further education on CAM, and up to $66.7 \%$ GPs favour the idea CAM should be included in medical curriculums.

A high uptake of CAM among New Zealand healthcare professionals was identified by this review. The estimates of CAM practice and referral rates are comparable to those oversea figures: $20.6 \%$ of United Kingdom (UK) physicians used CAM [37] and 84\% of Australian rehabilitation physicians referred patients to CAM practitioners [38]. The overall positive attitude of

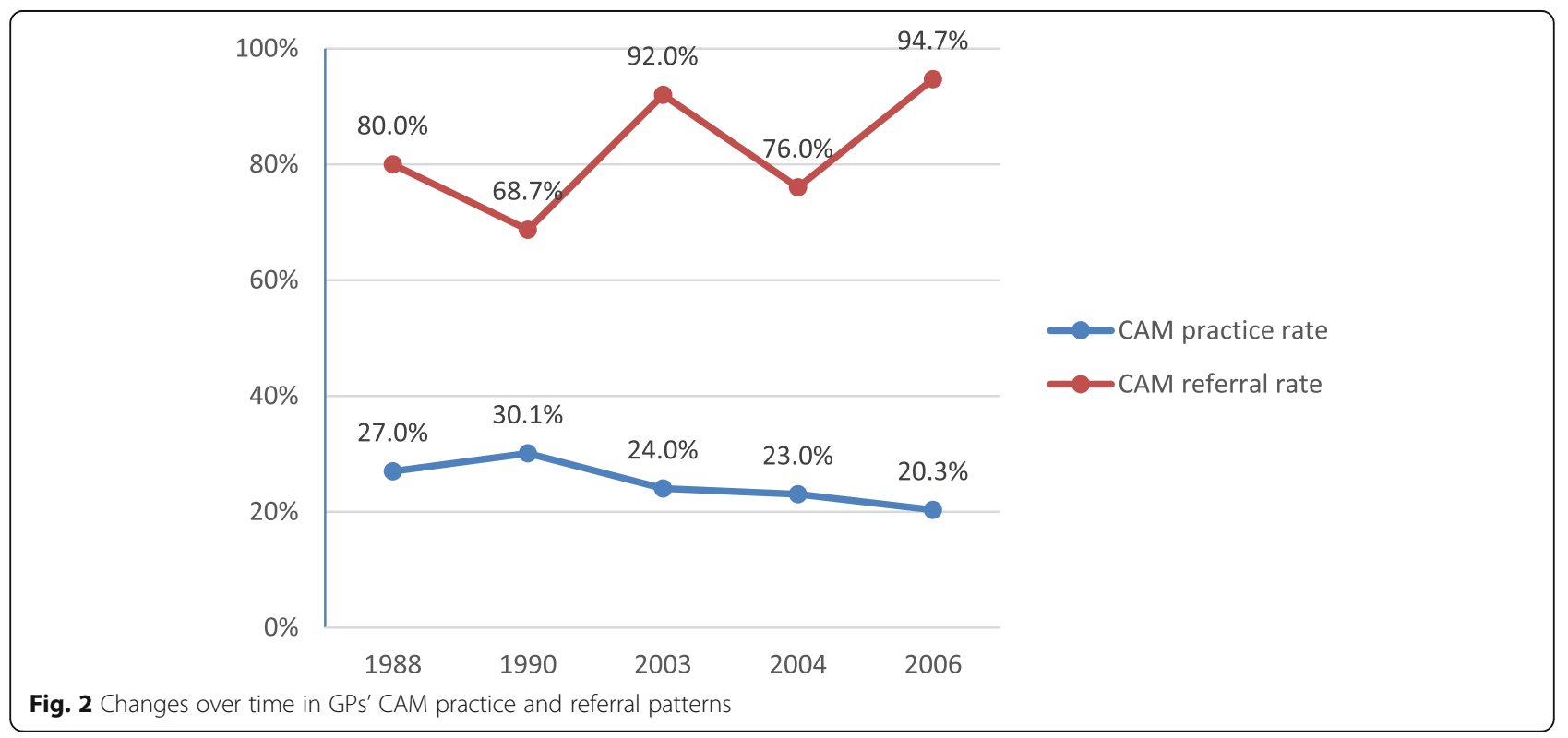


Table 3 Changes over time in GPs' opinions on the usefulness of specific CAM therapies

\begin{tabular}{llll}
\hline Year & 1st & 2nd & 3rd \\
\hline $1990[13]$ & Acupuncture & Massage & Hypnosis \\
$2003[3]$ & Acupuncture & Chiropractic & Hypnosis \\
$2006[14]$ & Acupuncture & Chiropractic & Osteopathy \\
\hline
\end{tabular}

CAM among New Zealand healthcare professionals is similar to those seen in as surveys of physicians in the UK $[39,40]$, with many healthcare professionals considering CAM as natural and effective, and regard the use of CAM as a complement to conventional therapy. The growing awareness of the importance of holistic health, where different aspects of health (mind, body, spirit, and lifestyle) combine to provide total wellbeing, as well as the need for culturally sensitive health services, are important factors that support consideration of the use of CAM [12, 15].

Our review showed the differences in referral patterns with respect to age, gender, and location of practice: the doctors who recommended CAM to a higher percentage of patients are more likely to be younger, female, and doctors who practice in the community (as opposed to a hospital). These results reflect similar patterns of clinical behaviours of healthcare professionals in the United States (US) and Canada [10]. Although these findings are interesting, as yet, there does not seem to be evidence to explain as to why this may be so. This perhaps indicates a changing culture, towards less conservative attitudes. This may be because of an increased exposure to CAM, and a higher likelihood of personal CAM use by younger physicians [10]. It may be because community doctors deal with a variety of health conditions, have more opportunities to address patients' total wellbeing, and tend to be more familiar with patients [15].

Alongside the growing interest and use of CAM among New Zealand healthcare professionals have come a rising concern over the risks of using CAM. This is especially the case given that many healthcare professionals have received limited (formal) training on CAM, and some practise CAM without training. This finding is consistent with the results of similar UK studies: a sizable proportion of physicians in the UK employed CAM, yet many have not received any training in CAM [37]. While it is argued that CAM practitioners should have

Table 4 Changes over time in GPs' practice patterns of specific CAM therapies

\begin{tabular}{llll}
\hline Year & 1st & 2nd & 3rd \\
\hline $1988[12]$ & Acupuncture & Chiropractic & Hypnosis \\
$1990[13]$ & Acupuncture & Osteopathy & Homeopathy \\
$2006[14]$ & Acupuncture & Herbal medicines & Homeopathy \\
\hline
\end{tabular}

Table 5 Changes over time in GPs' referral patterns for specific CAM therapies

\begin{tabular}{llll}
\hline Year & 1st & 2nd & 3rd \\
\hline $1988[12]$ & Acupuncture & Chiropractic & Hypnosis \\
$1990[13]$ & Acupuncture & Osteopathy & Massage \\
$2004[8]$ & Acupuncture & Homeopathy & Osteopathy \\
$2006[14]$ & Acupuncture & Chiropractic & Osteopathy \\
\hline
\end{tabular}

the 'standard' training and qualifications for CAM practice, this would also apply to conventional healthcare professionals who practise CAM. Specific training needs to be made available to enable them to meet expected standards of practice. In line with the findings of this review, in recent years there have been calls among healthcare professionals overseas (e.g., US and Germany) for further CAM education, and for the introduction of CAM courses in medical education institutions [41, 42]. National initiatives to integrate CAM elements in undergraduate medical education has been launched in a number of 'developed' countries including UK, US, Canada, Germany, and Australia [43]. Currently, CAM has been largely ignored in the undergraduate medical curriculum in New Zealand [9]; postgraduate courses on CAM are limited in universities, with postgraduate acupuncture courses for healthcare practitioners only available in University of Otago [44] and Auckland University of Technology [45]. GPs have consistently identified their limited knowledge about rongoā Māori and traditional Pacific Island medicine, but relevant education courses are still lacking. Despite the limited education resources, a number of medical professional and regulatory organizations in New Zealand, such as the Medical Council of New Zealand [46], the New Zealand College of Midwives [47], and New Zealand Nurses Organisation [48], have issued position statements endorsing the care standards of CAM practice, education, and knowledge. In responding to the increasing popularity and requirement for CAM, diverse training offerings including undergraduate, graduate clinical, and continuing education are warranted, which will inform healthcare professionals with up-to-date and scientific information.

To meet the challenges of managing CAM in New Zealand clinical settings, there is a need to encourage greater recognition, communication, and cooperation between conventional and CAM practitioners. Firstly, developing good inter-professional relationships will depend on an established common ground by way of adequate medical training and qualifications. Apart from the specific CAM training initiatives for conventional healthcare professionals (mentioned above), more formal medical training for CAM practitioners is essential. Such training could help reassure conventional healthcare professionals that CAM practitioners are able to 
communicate using a common medical language, and that serious conditions will not be unrecognized and inappropriately diagnosed, which are the concerns from GPs and pharmacists identified in the included two interview studies [33, 34].

Secondly, enhancing CAM credibility and acceptability to conventional healthcare professional will depend on established regulatory standards. As noted in the included studies, the relative hesitancy of healthcare professionals is partly due to the current absence of regulation for CAM, and the apparent lack of accountability [33, 34]. Although there have been mixed views to the regulation form (mandatory or self-regulation), healthcare professionals support proposals for national regulations for CAM. Chiropractic and osteopathy are the only two CAM therapies that have been regulated under the HPCA Act 2003 [18]. It is acknowledged that full regulation of CAM in line with requirement of conventional medicines is problematic due to the wide variety of therapies under the CAM umbrella, and the relevant negative impacts on CAM market [34]. It would be more appropriate and feasible to introduce more regulations for the ones that are widely accepted and used by New Zealand healthcare professionals, for example, acupuncture. Chinese Medicine (which includes acupuncture) has being considered for regulation over the past five years. However, progress has been relatively slow with political and industry opposition, and no such regulatory has yet been made (unpublished: internal updates to members of New Zealand Acupuncture Standards Authority).

Thirdly, more efforts and supports from the government and private sector are needed to enhance the evidence base of CAM therapies. Many of the healthcare professionals in our review highlighted the lack of scientific evidence as a major concern about CAM, and the fact that their advice to patients on CAM is based on evidence. CAM research has been largely lacking in New Zealand: taking acupuncture for instance, five clinical trial studies on acupuncture were conducted in New Zealand since 2000 (identified by the Australian New Zealand Clinical Trials Registry [ANZCTR] [49]), compared to 75 in Australia (identified by ANZCTR [50]), and 70 in the UK (identified by the International Standard Randomised Controlled Trial Number [ISRCTN] [51]). It is frustrating, however, not surprising, to note the cycle of 'lack of funding - lack of research - absence of evidence' on CAM in New Zealand. It may not be pragmatic to set CAM as a priority for New Zealand funding bodies in the short term, but establishing open and non-judgemental perspectives on CAM research is encouraged. While CAM practitioners are supportive of evidence-based practice, absence of available evidence, industry support, and skills are perceived as the main barriers to evidence-based practice uptake [52]. Given that the research environment of CAM in
New Zealand, in order to form a coordinated research activity and ensure appropriate scientific research quality, a CAM-based practice-based research network (which affiliates academic institutions and clinical practices to ask and answer community-based healthcare questions and translate research findings into practice) [53] may be a potential solution to better address contemporary CAM research needs in New Zealand.

Previous studies reported that physicians are more negative compared to other healthcare professionals, and nurses are found to be more accepted to CAM $[9,10]$. This review was unable to compare the differences in clinical behaviours and attitudes between healthcare professionals due to a lack of studies of the healthcare professionals other than GPs. For the included studies on allied healthcare professionals (nurses, midwives, pharmacists and physiotherapists), the investigated CAM modalities, research questions, and methodology approaches were heterogeneous. Future research is needed to compare the practice of, attitudes toward, and knowledge about CAM amongst different categories of healthcare professionals, and advance the understanding of values and roles CAM in New Zealand healthcare systems. To enable direct comparisons, measurements of attitudes and knowledge require the use of reliable instruments, which are yet to be developed.

This is the first work that synthesises New Zealand healthcare professionals' practice of, attitudes toward, and knowledge about CAM. This review summarized the results of existing quantitative and qualitative studies. To enhance its internal and external validity, this review strictly followed the methodology framework for integrative reviews, as well as the recommendations of the PRIS MA statements. Nine of the 11 included studies were of moderate to high quality, thus enhancing the reliability of the review findings. This notwithstanding, there are limitations to be considered when interpreting the results. The definition of CAM used in the included studies raises difficulties in a review of this sort as there is a lack of consensus on what is meant by CAM. In addition, the low response rates in some surveys may introduce bias into research results that those healthcare professionals with strong views for or against CAM, may be overrepresented.

\section{Conclusions}

Based upon the included 11 studies (two of 'high-quality', seven of 'moderate-quality', and two of 'low-quality'), it was demonstrated that in order to better manage CAM in New Zealand clinical settings, there is a need to invest in CAM research and education, and enhance CAM regulation. This review is a first step in developing an evidence base to offer insights for further development of effective CAM policies regarding safety, efficacy, regulation and integration in $\mathrm{New}$ Zealand. 


\section{Supplementary Information}

The online version contains supplementary material available at https://doi. org/10.1186/s12906-021-03235-z.

Additional file 1. Risk of bias assessment of eight surveys by using the Hoy 2012 tool.

Additional file 2. Risk of bias assessment of three qualitative studies by using the CASP checklist.

\section{Abbreviations}

CAM: Complementary and alternative medicine; GP: General practitioner; MACCAH: Ministerial Advisory Committee on Complementary and Alternative Health; ACC: Accident Compensation Corporation; PRIS MA: Preferred Reporting Items for Systematic Reviews and Meta-Analyses; HPCA: Health Practitioners Competence Assurance; CASP: Critical Appraisal Skills Programme; UK: United Kingdom; US: United States; ANZCTR: Australian New Zealand Clinical Trials Registry; ISRCTN: International Standard Randomised Controlled Trial Number

\section{Acknowledgements}

The authors wish to thank Thelma Fisher for her assistant with the search strategy development.

\section{Authors' contributions}

LL: review concept and design, literature search and selection, data extraction, methodological quality assessment, data analysis and interpretation, drafting and revision; YT: literature search and selection, data extraction, methodological quality assessment and revision; GDB, HY, ST: review design and revision. All authors read and approved the final manuscript.

\section{Funding}

This work was supported by the Project First-Class Disciplines Development of the Chengdu University of Traditional Chinese Medicine (CZYHW1901), the Science \& Technology Department of Sichuan Province (2018HH0123,2021YFH0096), the 2018 New Zealand-China NonCommunicable Diseases Emerging Researcher Travel Grant, and the 2019 Internationalization Incentive Fund, Division of Health Sciences, University of Otago. The funding sources built international collaboration platform for the team, and had no role in this paper other than providing funding support for publishing.

\section{Availability of data and materials}

All data generated or analysed during this study are included in this published article and its supplementary information files.

\section{Ethics approval and consent to participate} Not applicable.

\section{Consent for publication}

Not applicable.

\section{Competing interests}

$L L$ is a registered acupuncturist in New Zealand, and currently a member of the New Zealand Acupuncture Standards Authority (since March 2015).

\section{Author details}

${ }^{1}$ Centre for Health, Activity, and Rehabilitation Research, School of Physiotherapy, University of Otago, PO Box 56, Dunedin 9054, New Zealand. ${ }^{2}$ China-New Zealand Collaboration Centre for Integrative Medicine (CHINZIM), University of Otago, Dunedin, New Zealand. ${ }^{3}$ Acupuncture \& Tuina School, Chengdu University of Traditional Chinese Medicine, Chengdu, China. ${ }^{4}$ China-New Zealand Collaboration Centre for Integrative Medicine (CHINZIM), Chengdu University of Traditional Chinese Medicine, Chengdu, China. ${ }^{5}$ Acupuncture \& Chronobiology Key Laboratory of Sichuan Province, Chengdu, China.
Received: 9 September 2020 Accepted: 1 February 2021

Published online: 13 February 2021

\section{References}

1. Nuffer M. Chapter 27 - Integrative Health and Medicine: Dietary Supplements and Modalities for the Treatment of Obesity. In: Watson RR, editor. Nutrition in the Prevention and Treatment of Abdominal Obesity (Second Edition). Elsevier: Academic Press; 2019. p. 393-408.

2. Ministerial Advisory Committee on Complementary and Alternative Health. Complementary and Alternative Medicine: Current Policies and Policy Issues in New Zealand and Selected Countries. A Discussion Document 2003. Wellington: Ministry of Health; 2003

3. Taylor M. Patients' and general practitioners' attitudes towards complementary medicine in Wanganui, New Zealand. New Zealand Fam Physician. 2003;30:102-7.

4. Nicholson T. Complementary and alternative medicines (including traditional Maori treatments) used by presenters to an emergency department in new Zealand: a survey of prevalence and toxicity. N Z Med J. 2006;119(1233):U1954

5. Chrystal K, Allan S, Forgeson G, Isaacs R. The use of complementary/ alternative medicine by cancer patients in a New Zealand regional cancer treatment Centre. N Z Med J. 2003;116(1168):U296.

6. Ministry of Health. A portrait of health: key results of the 2006/07 New Zealand health survey. Wellington: Ministry of Health; 2008.

7. Ministerial Advisory Committee on Complementary and Alternative Health. Complementary and Alternative Health Care in New Zealand: Advice to the Minister of Health. Wellington: Ministerial Advisory Committee on Complementary and Alternative Health; 2004.

8. Lawler S, Cameron L. Massage therapy and complementary and alternative medicine: attitudes and use among general practitioners and patients in Auckland, New Zealand. New Zealand Fam Physician. 2004;31:229-38.

9. Lo S. Perceptions and attitudes of New Zealand Plunket nurses toward the use of complementary and alternative medicine in children. Auckland, New Zealand: Unitec Institute of Technology; 2012.

10. Sewitch MJ, Cepoiu M, Rigillo N, Sproule D. A literature review of health care professional attitudes toward complementary and alternative medicine. Complement Health Pract Rev. 2008;13(3):139-54.

11. Ministry of Health. Health of the health workforce 2015. Wellington: Ministry of Health; 2016.

12. Hadley CM. Complementary medicine and the general practitioner: a survey of general practitioners in the Wellington area. N Z Med J. 1988;101(857): 766-8.

13. Marshall RJ, Gee R, Israel M, Neave D, Edwards F, Dumble J, et al. The use of alternative therapies by Auckland general practitioners. N Z Med J. 1990; 103(889):213-5.

14. Poynton L, Dowell A, Dew K, Egan T. General practitioners' attitudes toward (and use of) complementary and alternative medicine: a New Zealand nationwide survey. N Z Med J. 2006:119(1247):U2361.

15. Bocock C, Reeder Al, Perez D, Trevena J. Beliefs of New Zealand doctors about integrative medicine for cancer treatment. Integr Cancer Ther. 2011; 10(3):280-8

16. Whittemore R, Knafl K. The integrative review: updated methodology. J Adv Nurs. 2005;52(5):546-53.

17. Moher D, Liberati A, Tetzlaff J, Altman DG. Preferred reporting items for systematic reviews and meta-analyses: the PRISMA statement. PLoS Med. 2009:6(7):e1000097.

18. Ministry of Health. Responsible authorities under the Act [cited 2020 April 29]. Available from: https://www.health.govt.nz/our-work/regulation-health-a nd-disability-system/health-practitioners-competence-assurance-act/ responsible-authorities-under-act.

19. Hoy D, Brooks P, Woolf A, Blyth F, March L, Bain C, et al. Assessing risk of bias in prevalence studies: modification of an existing tool and evidence of interrater agreement. J Clin Epidemiol. 2012:65(9):934-9.

20. CASP Checklist: 10 questionsto help you make sense of a qualitative research 2018 [cited 2020 April 30]. Available from: https://casp-uk.net/wpcontent/uploads/2018/01/CASP-Qualitative-Checklist-2018.pdf

21. Gardner T, Refshauge K, Smith L, McAuley J, Hubscher M, Goodall S. Physiotherapists' beliefs and attitudes influence clinical practice in chronic low back pain: a systematic review of quantitative and qualitative studies. J Physiother. 2017;63(3):132-43. 
22. Fullen BM, Baxter GD, O'Donovan BGG, Doody C, Daly L, Hurley DA. Doctors' attitudes and beliefs regarding acute low back pain management: a systematic review. PAIN. 2008;136(3):388-96.

23. Lewis GRJ. Should doctors discourage nutritional supplementation? A cardiovascular perspective. Heart Lung Circ. 2004;13(3):245-51.

24. Te Huia M. Relationships and implications for complementary and alternative medicine in Aotearoa New Zealand: a discussion paper. Nurs Prax N Z. 2019;35(3):25-32.

25. Stapleton $\mathrm{P}$, Chatwin H, Crebbin S, Smith D, Boucher E, Scott S, et al. Use of complementary therapies by registered psychologists: an international study. Professional Psychol Res Pract. 2015;46(3):190-6.

26. Best M, Butow P, Olver I. Palliative care specialists' beliefs about spiritual care. Support Care Cancer. 2016;24(8):3295-306.

27. Dew K, Plumridge E, Stubbe M, Dowell T, Macdonald L, Major G. 'You just got to eat healthy': the topic of CAM in the general practice consultation. Health Sociol Rev. 2008;17(4):396-409.

28. Oliver C, Watson C, Crowley E, Gilroy M, Page D, Weber K, et al. Vitamin and mineral supplementation practices in preterm infants: a survey of Australian and New Zealand neonatal intensive and special care units. Nutrients. 2020; 12(1):51.

29. Smith JM, Sullivan SJ, Baxter GD. Massage therapy: more than a modality. N Z J Physiother. 2010;38(2):44-51.

30. Holt S. Which natural products do New Zealand GPs and pharmacists take themselves and/or recommend to patients? Adv Integr Med. 2014;1(2):85-6.

31. Holt S, Gilbey A. A survey of New Zealand general Practitioners' understanding of CAM therapies and recommendations they make. Focus Altern Complement Ther. 2011:16(2):189-90.

32. Harding D, Foureur M. New Zealand and Canadian midwives' use of complementary and alternative medicine. NZ Coll Midwives J. 2009;40:7-12.

33. Upsdell $M$, Jaye C. Engaging with complementary and alternative medicine in general practice. J Primary Health Care. 2011;3(1):29-34.

34. Barnes J, Butler R. Community pharmacists' views on the regulation of complementary medicines and complementary-medicines practitioners: a qualitative study in New Zealand. Int J Pharm Pract. 2018;26(6):485-93.

35. McDowell JM, Kohut SH, Betts D. Safe acupuncture and dry needling during pregnancy: New Zealand physiotherapists' opinion and practice. J Integr Med. 2019;17(1):30-7.

36. Anwar M, Norris P, Green J, Au S, Li G, Ma M, et al. Pharmacy students' use of and beliefs about traditional healthcare. J Immigr Minor Health. 2015; 17(3):895-904

37. Posadzki P, Alotaibi A, Ernst E. Prevalence of use of complementary and alternative medicine (CAM) by physicians in the UK: a systematic review of surveys. Clin Med (Lond). 2012;12(6):505-12.

38. Mak JC, Mak LY, Shen Q, Faux S. Perceptions and attitudes of rehabilitation medicine physicians on complementary and alternative medicine in Australia. Intern Med J. 2009:39(3):164-9.

39. Lewith GT, Hyland M, Gray SF. Attitudes to and use of complementary medicine among physicians in the United Kingdom. Complement Ther Med. 2001;9(3):167-72

40. Fearon J. Complementary therapies: knowledge and attitudes of health professionals. Paediatr Nurs. 2003;15(6):31-5.

41. Münstedt K, Harren H, von Georgi R, Hackethal A. Complementary and alternative medicine: comparison of current knowledge, Attitudes and Interest among German Medical Students and Doctors. Evid Based Complement Alternat Med. 2011;2011:790951.

42. Ziodeen KA, Misra SM. Complementary and integrative medicine attitudes and perceived knowledge in a large pediatric residency program. Complement Ther Med. 2018;37:133-5.

43. Quartey NK, Ma PHX, Chung VCH, Griffiths SM. Complementary and alternative medicine education for medical profession: systematic review. Evid Based Complement Altern Med. 2012;2012:656812.

44. Postgraduate study in Acupuncture [cited 2020 June 25]. Available from: https://www.otago.ac.nz/physio/postgraduate/otago057240.html.

45. Acupuncture - Postgraduate Certificate in Health Science [cited 2020 June 25]. Available from: https://www.aut.ac.nz/study/study-options/healthsciences/courses/postgraduate-certificate-in-health-science/acupuncture.

46. Medical Council of New Zealand. Doctors and CAM (complementary and alternative medicine) 2017. Available from: https://www.mcnz.org.nz/assets/ standards/7eb60db2d2/Doctors-and-CAM-Complementary-and-alternativemedicine.pdf.
47. New Zealand College of Midwives. Consensus Statement: Complementary and Alternative Therapies 2019. Available from: https://www.midwife.org.nz/ wp-content/uploads/2019/05/Complementary-and-Alternative-Therapies.pdf.

48. New Zealand Nurses Organization. Rongoā Māori and complementary therapies in nursing practice. 2011.

49. Trial Search - ANZCTR [cited 2020 June 29]. Available from: https://www.a nzctr.org.au/TrialSearch.aspx\#\&\&conditionCode=\&dateOfRegistrationFrom= \&interventionDescription=acupuncture\&interventionCodeOperator= OR\&primarySponsorType $=\&$ gender $=\&$ distance $=\&$ postcode $=\&$ pageSize $=20 \& \mathrm{a}$ geGroup=\&recruitmentCountryOperator=OR\&recruitmentRegion= \&ethicsReview=\&countryOfRecruitment=New+Zealand\&registry=\&sea $r c h T x t=\&$ studyType $=\&$ allocationTolntervention $=\&$ dateOfRegistrationTo= \&recruitmentStatus=\&interventionCode $=$ \&healthCondition $=$ \&hea Ithy Volunteers=\&page $=1 \&$ conditionCategory $=\&$ fundingSource $=\&$ trialStartDa teTo=\&trialStartDateFrom $=\&$ phase $=$.

50. Trial Search - ANZCTR [cited 2020 July 3]. Available from: https://www.a nzctr.org.au/TrialSearch.aspx\#\&\&conditionCode=\&dateOfRegistrationFrom= \&interventionDescription=acupuncture\&interventionCodeOperator $=$ OR\&primarySponsorType $=\&$ gender $=\&$ distance $=\&$ postcode $=\&$ pageSize $=20 \& a$ geGroup=\&recruitmentCountryOperator=OR\&recruitmentRegion= \&ethicsReview=\&countryOfRecruitment=Australia\&registry=\&searchTxt= \&studyType=\&allocationTolntervention $=\&$ dateOfRegistrationTo $=$ \&recruitmentStatus=\&interventionCode=\&healthCondition $=$ \&hea IthyVolunteers $=\&$ page $=4 \&$ conditionCategory $=\&$ fundingSource $=\&$ trialStartDa teTo=\&trialStartDateFrom $=\&$ phase $=$

51. ISRCTN registry [cited 2020 June 29]. Available from: https://www.isrctn. com/search?q=acupuncture\&filters=recruitmentCountry\%3AUnited+ Kingdom\&searchType=basic-search.

52. Leach MJ, Gillham D. Are complementary medicine practitioners implementing evidence based practice? Complement Ther Med. 2011;19(3): 128-36.

53. Graham DG, Spano MS, Stewart TV, Staton EW, Meers A, Pace WD. Strategies for planning and launching PBRN research studies: a project of the academy of family physicians National Research Network (AAFP NRN). J Am Board Fam Med. 2007;20(2):220-8.

\section{Publisher's Note}

Springer Nature remains neutral with regard to jurisdictional claims in published maps and institutional affiliations.

\section{Ready to submit your research? Choose BMC and benefit from:}

- fast, convenient online submission

- thorough peer review by experienced researchers in your field

- rapid publication on acceptance

- support for research data, including large and complex data types

- gold Open Access which fosters wider collaboration and increased citations

- maximum visibility for your research: over $100 \mathrm{M}$ website views per year

At BMC, research is always in progress.

Learn more biomedcentral.com/submissions 